Raya Abbas

\title{
Die Vermögensbeziehungen der Ehegatten und nichtehelichen Lebenspartner im serbischen Recht
}

Eine Untersuchung des Sach- und Kollisionsrechts unter Berücksichtigung der Staatensukzession im IPR

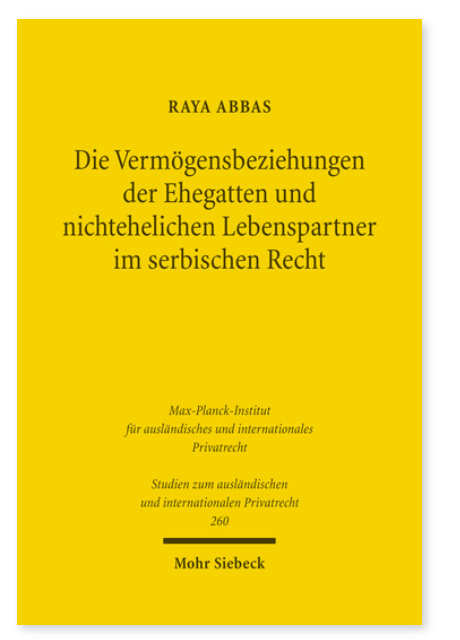

2011. XXI, 297 Seiten. StudIPR 260

ISBN 978-3-16-151445-6

DOI 10.1628/978-3-16-151445-6

eBook PDF 74,00€

ISBN 978-3-16-150847-9

fadengeheftete Broschur $74,00 €$
Der Zerfall des ehemaligen Jugoslawiens und die dadurch hervorgerufene Rechtszersplitterung in den unabhängigen Teilrepubliken haben eine erhebliche Rechtsunsicherheit für den deutschen Rechtsanwender mit sich gebracht. Raya Abbas durchleuchtet die verschiedenen Rechtsordnungen und erforscht das jeweils geltende Güterrecht. Sie untersucht den serbischen gesetzlichen Güterstand der Errungenschaftsgemeinschaft und die Ehevertragsfreiheit. Einen weiteren Schwerpunkt bildet das Recht der nichtehelichen Lebensgemeinschaft, die neben der Ehe eine eigenständige Institution darstellt. Die Autorin befasst sich außerdem mit der besonderen Problematik der Staatensukzession im internationalen Privatrecht, die bei der Bestimmung des Güterstatuts ehemaliger jugoslawischer Staatsangehöriger relevant wird. In diesem Zusammenhang wird das Staatsangehörigkeitsrecht vor und nach dem Zerfall dargestellt, das auch im Hinblick auf das im internationalen Familienrecht regierende Staatsangehörigkeitsprinzip von Bedeutung ist und somit einem praktischen Bedürfnis Rechnung trägt.

Raya Abbas Geboren 1983; Studium der Rechtswissenschaft an der Universität Potsdam; 2009-11 Wissenschaftliche Mitarbeiterin am Lehrstuhl für Bürgerliches Recht, Internationales Privatrecht und Rechtsvergleichung derUniversität Potsdam; 2010 Promotion; seit Mai 2010 Rechtsreferendarin im Bezirk des Kammergerichts.

Jetzt bestellen:

https://mohrsiebeck.com/buch/die-vermoegensbeziehungen-der-ehegatten-und-nichtehelichen-lebenspartner-imserbischen-recht-9783161514456?no_cache $=1$

order@mohrsiebeck.com

Telefon: +49 (0)7071-923-17

Telefax: $+49(0) 7071-51104$ 